\title{
A criatividade e a experimentação na performance e docência performática em tempos de pandemia
}

\author{
Sonia Regina Albano de Lima \\ Universidade Estadual Paulista, Instituto de Artes \\ Saber Musical \\ soniaalbano@uol.com.br \\ https://orcid.org/0000-0001-6342-6103
}

\begin{abstract}
Resumo: O texto relata parte dos impactos ocorridos nas práticas musicais realizadas por profissionais e professores de performance após a instauração no planeta da COVID-19, fato que impôs aos seus profissionais a utilização de suportes virtuais, a fim de que essas ações não fossem paralisadas. Foram avaliados os prejuízos e os benefícios conquistados nessa pandemia pela utilização de práticas virtuais no ambiente performático como um todo e em que medida essa tecnologia poderá impactar a performance no futuro. No texto também foram introduzidos alguns depoimentos de profissionais ligados a realização de eventos musicais, participação em práticas musicais diversas, bem como depoimentos de professores de instrumento e canto que tiveram de utilizar a tecnologia para ministrarem suas aulas. Serviram de fundamentação teórica os textos do físico quântico Amit Goswami e do compositor Marcos Câmara de Castro, entre outros.
\end{abstract}

Palavras-chave: Experimentação performática, Instrumentistas, Cantores, Professores de performance, Criatividade.

\section{Creativity and Experimentation in The Performance and in The Performative Teaching in Pandemic Times}

\begin{abstract}
The text reports part of the impacts occurred in the musical practices carried out by performance professionals and teachers after the establishment of COVID-19 in the planet, a fact that imposed to their professionals the use of virtual supports so that these actions were not paralyzed. The losses and benefits conquered in this pandemic were analyzed by means of the use of virtual practices in the performative environment as a whole. It was also analyzed to what extent this technology can impact the performance in our future. In the text, some testimonies were further introduced by professionals linked to carrying out musical events and participation in several musical practices, as well as testimonies by instrument and singing professors who had to make use of the technology in order to present their lessons. The texts by the Quantic physicist Amit Goswami and by the composer Marcos Câmara de Castro, among others, served as theoretical foundation.
\end{abstract}

Keywords: Performative experimentation, Instrumentalists, Singers, Performance professors, Creativity. 


\title{
A criatividade e a experimentação na performance e docência performática em tempos de pandemia
}

\author{
Acreditamos que somos seres soberanos \\ frente ao mundo, no entanto, \\ periodicamente somos afrontados por \\ infortúnios naturais que para nos \\ mantermos vivos física, cultural e \\ socialmente é necessário utilizarmos \\ nossa criatividade - um dom natural \\ que ainda não nos foi tirado.
}

O texto que se segue pretende discorrer sobre os impactos ocorridos na performance musical, seja em atividades ligadas à docência, seja na atuação profissional dos instrumentistas, cantores e regentes, após a instauração da COVID-19 em todo o planeta. Com início no final de 2019, esta pandemia fez com que os indivíduos adotassem medidas de prevenção, a maior delas, o distanciamento social que obrigou o fechamento das escolas, locais públicos e espaços culturais. O vírus alastrou-se de forma abrupta no mundo, obrigando as diversas áreas de conhecimento a se adequarem a uma nova proposta de atuação. No que se reporta ao ambiente musical, tanto os performers quanto os docentes dessa área, tiveram que recorrer aos meios tecnológicos e ambientes virtuais para propagação de suas ações. Cabe a nós avaliar em que medida essa situação impactou a área, por quanto tempo ela se estenderá e em que proporções ela será capaz de alterar, no futuro, os meios de divulgação das práticas musicais e as metodologias de ensino já instauradas e bastante solidificadas.

Esse vírus tem se proliferado há meses e exigiu da parte dos profissionais e docentes ligados ao setor artístico, tomadas de posições rápidas que foram sendo aplicadas sem a possibilidade de uma análise mais atenta. As Artes, de modo geral, sofreram os maiores impactos em relação as demais áreas de conhecimento, considerando-se que habitualmente este setor depende da presença do público, o que implica em aglomerações - fato não permitido durante a pandemia.

As Escolas de Música, Conservatórios, Cursos Técnicos de Música, Universidades e Academias passaram a oferecer um ensino musical virtual. Aulas, oficinas, masterclasses, palestras e cursos que anteriormente eram ofertados presencialmente, seguiram em formato online; da mesma forma, os concertos, as óperas, shows de música popular e demais atividades performáticas. 
A adoção dessas práticas beneficiou parte da população que pode assistir a essas apresentações gratuitamente em seus tablets, smartphones e computadores, e, por vezes, realizar cursos de música por um custo muito inferior ao dos cursos presenciais, ou até mesmo cursos gratuitos. Houve um aumento considerável das atividades performáticas veiculadas gratuitamente nos meios digitais, o que promoveu o aumento de internautas que tiveram acesso a essa produção. Esses benefícios não se estenderam para a camada mais pobre da sociedade sem acesso à internet, muitos deles, alunos matriculados em Projetos Culturais destinados ao ensino de instrumento e canto que foram encerrados por não terem condições de disponibilizar outras formas de ensino não presencial.

As ações voltadas para a pesquisa performática tiveram um avanço expressivo. Congressos virtuais nacionais e internacionais foram intensificados por um custo bem menor, tanto para os organizadores como para os participantes e palestrantes. Proliferaram os textos científicos e as palestras no ambiente virtual. De maneira geral, aulas online, congressos virtuais, palestras, oficinas, debates, lives e webnário com educadores, artistas nacionais e internacionais, regentes, instrumentistas e educadores tiveram uma sensível ascensão, na tentativa de dar continuidade às atividades anteriormente presenciais.

A título de exemplo, podemos citar o Festival Internacional de Música em Casa (FIMUCA), um festival virtual com amplo alcance, atingindo estudantes e artistas de todo o Brasil e de diversas partes do mundo. Realizado pela Escola de Música da Universidade Federal do Rio Grande do Norte (EMUFRN), este evento teve início em final de junho de 2020, estendendo-se até julho e ofertou inúmeras atividades de ensino e aprendizagem musical, aulas, apresentações musicais a distância, utilizando a plataforma EMUFRN online (ead.music.ufrn.br) e um software de webconferência, promovendo um ambiente educativo e participativo para um festival de música realizado com recursos tecnológicos digitais, além de um convívio intenso entre os participantes ${ }^{1}$. Conforme expresso pelos organizadores desse evento, o FIMUCA surgiu da compreensão que os festivais são ambientes ricos de interação e aprendizagem no âmbito musical e que as tecnologias

\footnotetext{
${ }^{1}$ As informações obtidas deste Festival foram retiradas do texto que está no prelo, intitulado O Festival Internacional de Música em Casa: tecnologias, aprendizagens e práticas musicais em tempos de COVID19, de autoria de Flavio Gabriel et allium.
} 
digitais de informação e comunicação (TDIC) podem estruturar e possibilitar vivências musicais diversas com baixo custo, o que beneficia sobremaneira a realização de novas práticas.

Foram convidados professores de instrumentos que atuam nas orquestras sinfônicas, professores de composição, violão, saxofone e eufônio que deveriam dar aulas online, realizar concertos nas redes sociais, participar de mesas redondas discutindo temas de interesse geral. Em média este festival pode contar com um número expressivo de mais de 200 professores participantes. Vejamos o relato de um dos organizadores:

\begin{abstract}
Com o intuito de reproduzir ao máximo a sensação de participação em um festival internacional de música, optamos por utilizar a plataforma $\mathrm{EaD}$ da EMUFRN. Nesse espaço, além do acesso às aulas ao vivo, os professores convidados poderiam disponibilizar materiais complementares em diversos formatos como pdf, videos, ppt, dentre outros. O acesso através de inscrição prévia com geração de login e senha também permitiria o controle de frequência dos estudantes bem como a emissão de certificados (MAIORINO et all., 2020, no prelo).
\end{abstract}

A OSESP (Orquestra Sinfônica do Estado de São Paulo), a Orquestra Sinfônica de Porto Alegre, a Orquestra Sinfônica da Bahia, a Orquestra Filarmônica de Goiás e a Orquestra Filarmônica de Minas Gerias cederam seus concertos gratuitamente. As mesas redondas contemplaram temas bastante diversificados, entre eles: a ópera no Brasil, questões acerca da gestão cultural, estruturas e relações de poder no âmbito musical, bandas de música e bandas sinfônicas e um debate sobre a atuação do músico independente. Uma das coisas mais relevantes do FIMUCA foi entender que um festival online, realizado em meio à uma pandemia mundial atraiu cerca de 30 mil inscritos nacionais e internacionais interessados em aprender e discutir música. Isso dificilmente ocorreria em um festival presencial, o que demonstra que tanto os congressos como os festivais de música online poderão se estender para o futuro.

Contudo, há muita insegurança com relação a continuidade da adoção do formato digital no ensino e na produção artística musical. Presume-se, de momento, que depois do planeta vencer esta pandemia, as práticas performáticas serão mais intensas nos canais digitais e o ensino musical sofrerá uma reestruturação acentuada, privilegiando mais intensamente as ações virtuais e o ensino a distância. Entretanto não podemos ignorar a crise financeira que se instaurou nas orquestras, nos teatros, nas casas de óperas e nos shows de música popular. No cenário voltado para a música erudita, as temporadas artísticas que há muito mantinham as grandes orquestras, tiveram de ser canceladas, o 
que dificultou em muito os organizadores dessas atividades em manter apresentações de qualidade ou até mesmo continuarem a realizar esses espetáculos. Foi necessário recriar formações orquestrais menores no formato de streaming e concertos nas plataformas digitais, como o YouTube, Instagram, Facebook, entre outros, o que permitiu que não assinantes dessas temporadas participassem gratuitamente dessa programação.

Com relação aos professores de performance, verificou-se que muitos deles não se sentiram confortáveis para ministrar aulas online, tendo em vista que as aulas presenciais priorizam, de forma intensa, a comunicação direta do professor com seu aluno, seja em aulas individuais, seja em aulas coletivas e afastam esses docentes do ambiente virtual, o que lhes parece bastante precário ainda. A comunicação presencial no aprendizado performático é importantíssima. Questões envolvendo embocadura, respiração, arcadas, dedilhados, posicionamento das mãos, dos braços, entre outras, são resolvidas em um piscar de olhos quando o docente está em contato direto com o seu aluno. Não obstante, as aulas online de instrumento e canto, devido à falta de equipamentos digitais de boa qualidade (microfones, interface digital, computadores e internet), oferecem uma captação sonora de má qualidade. Há muita dificuldade por parte desses professores de ensinarem práticas performáticas coletivas, formarem grupos de câmara e atuarem diretamente com seus alunos. Sendo assim, se essa prática se estender para o futuro, será necessário um investimento maior nos equipamentos eletrônicos, sem contar a necessidade de repensar como se processará o ensino performático.

A performance deve muito à tecnologia, seja na criação de aparelhos destinados à gravação, modificação e reprodução de sinais de áudio, seja na transmissão da mensagem musical ou na criação e aperfeiçoamento de instrumentos musicais e eletrônicos. Ao longo de sua evolução, os instrumentos musicais foram se remodelando, objetivando maior controle sonoro e uma expansão sonora mais expressiva por conta da tecnologia. Nesse sentido, para o futuro, após essa pandemia, o mundo poderá encontrar mudanças sistemáticas e novas tecnologias que trarão para a música resultados positivos, como os ocorridos em 1900 com a invenção do fonógrafo, rádio microfone e amplificação. A tecnologia de áudio nesse período alterou significativamente o cenário musical e uma infinidade de recursos técnicos se fez presente. As inovações tecnológicas criaram uma grande mudança nas expectativas e gostos do público, ainda que houvesse na época um 
enorme descontentamento e descrença por parte dos músicos. O compositor Celso Mojola assim se pronuncia com respeito ao surgimento da gravação:

[...] falsas ou não, as gravações vieram para ficar, e constituem hoje uma influente realidade no modo com as pessoas se relacionam com a música. [...] um grande número de apreciadores relaciona-se com a música de concerto sem nunca ter ido a uma sala de concertos [...] Os músicos executantes também são influenciados por esse fenômeno. Muitos usam gravações para orientar as suas execuções, outros acabam preocupando-se demasiadamente com problemas técnicos das obras, e desejam com meta principal uma execução sem erros. Ao que parece essa preocupação excessiva com notas erradas foi uma consequência direta da possibilidade de congelamento da execução de uma peça através do registro fonográfico. Nessa sequência de raciocínio facilmente chegamos em interpretações padronizadas e que, por vezes, demonstram pouca sensibilidade para outros aspectos expressivos de uma performance (MOJOLA, 1999, p. 1).

Mojola, em seu texto, toma como exemplo uma fala de Charles Rosen bastante expressiva em favor das gravações, ao se reportar às realizadas pelo célebre pianista Glenn Gould. Ele relata que a música para cravo de J. S. Bach nunca foi pensada para uma execução em sala de concertos. Há aspectos dessa música que seriam inteligíveis e apenas destacados para o intérprete. Para ele há uma grande quantidade de condução das vozes no Cravo Bem Temperado, que alguém, naquele período, pudesse ser capaz de ouvir como as vozes caminhavam juntas:

\begin{abstract}
Uma voz combina-se com a outra, e você consegue uma bonita mistura no cravo a menos que se utilize um estranho tipo de fraseado. E não há nenhuma evidência de que esse fraseado foi alguma vez empregado no tempo de Bach. Uma grande parte do fraseado do cravo de hoje é concebida para fazer essa música inteligível para o público, e eu penso francamente que a maneira como os cravistas tocam essa música com o objetivo de torná-la interessante e destacada para uma performance pública é mais distorcido do que as coisas que Glenn Gould realiza no piano (ROSEN, 1993, apud Mojola, 1999, p. 6-7).
\end{abstract}

Um texto recente do compositor brasileiro Dr. Marcos Câmara de Castro (2020), relata com muita propriedade a importância das gravações nas pesquisas performáticas. Pautado na publicação de Nicholas Cook intitulada Beyond the score - music as performance (2013), Marcos Câmara relata que um século de gravações enseja um rico campo de investigação dos mais recentes documentos históricos, conhecendo suas circunstâncias de produção e circulação. As informações que se seguem foram extraídas do livro de Nicholas Cook (2013, p. 139-142): 
Mais de um século de gravações oferece ao pesquisador não apenas a dimensão histórica abundantemente representada, mas também os instrumentos, os conjuntos e gêneros, a partir da gravação elétrica, em meados de 1920 [p. 139-140]. As gravações, a princípio, representam a totalidade do evento sonoro, se considerarmos as limitações tecnológicas de cada mídia - desde os rolos de piano, passando pelas gravações em 78 rpm, até os CDs -, quando nos abrem uma "janela para o passado", com sua equalização suspeita, fazendo com que certas coisas possam ser seguramente deduzidas enquanto que outras não, pelo menos até meados de 1920, com o advento da gravação elétrica, depois o 33 RPM, em fins dos anos 1940, o estéreo, no final de 1950 e o CD, no início dos anos 1980. Todas essas técnicas permitiam, dentro de suas limitações, imaginar o que se passava na sala de concerto, até que a gravação por fita magnética, em várias pistas, superasse todas as anteriores e se tornasse a norma (CÂMARA DE CASTRO, 2020). ${ }^{2}$

Marcos Câmara considera que a gravação representou uma mudança radical na democratização da alta cultura, e para a maioria dos consumidores, a música - clássica ou não - é música gravada. Ele considera, embasado na narrativa de N. Cook, que pensar a sala de concerto e o estúdio de gravação como original e cópia é uma maneira completamente inadequada de pensar a música:

Sempre haverá razões para se fazer música desta ou daquela maneira e cada uma delas terá suas consequências que poderão ser exploradas e avaliadas. Há inúmeras maneiras de produzir sentido na música como performance e vários sentidos para assim fazê-lo. É realmente assim: tão simples e tão complicado (CÂMARA DE CASTRO, 2020).

Câmara de Castro afirma que mesmo no século XXI, ainda há uma relutância por parte dos musicólogos em aceitar a música gravada como um fenômeno musical em si mesmo em lugar de uma substituição de alguma outra coisa. A música clássica é, em primeiro lugar, um evento e por isso a performance ao vivo permanece como a base essencial da música clássica, a despeito da primazia das gravações na vida da maioria dos ouvintes modernos. No reino da música clássica, noções persistentes de texto e obra compeliram os músicos a classificar a gravação mais como um processo tecnológico do que um processo artístico e estético: em outras palavras, os técnicos de gravação são vistos como técnicos e não como músicos, exatamente como os sindicatos reivindicavam. No entanto, os técnicos têm exercido cada vez mais influência sobre como a música soa e como nós esperamos que ela soe, tanto na música popular quanto na clássica. Essas mudanças na imagem do som não têm sido registradas na musicologia, o que não é

\footnotetext{
${ }^{2} \mathrm{O}$ texto deste autor intitulado Além da partitura: ou elementos para uma musicologia da performance, encontra-se na publicação que está sendo organizada por mim, intitulada Performance sob uma perspectiva pluralista, que se encontra no prelo.
} 
exatamente uma surpresa, uma vez que a disciplina nunca foi boa em lidar com coisas que podem ser ouvidas, mas não lidas (COOK, 2013, p. 352-377).

O texto deste compositor de certa maneira incita-nos a pensar que as mudanças tecnológicas do futuro poderão trazer benefícios tanto para a escuta musical, quanto na forma como se processará a produção musical. Temos assistido cada vez mais, no cenário musical atual, a intenção dos profissionais e docentes de performance criarem experiências musicais das mais inusitadas, desafiando o cenário musical tradicional instaurado a anos. De certa forma as apresentações compartilhadas no YouTube e nas redes sociais, expressam uma criatividade por parte dos músicos e docentes de performance até então desconhecida. Preocupações em obter a melhor sonoridade deixam de ter importância na atual conjuntura, em razão da necessidade de se criar uma sonoridade virtual capaz de manter o cenário musical ativo. Onde essa onda nos levará só o tempo dirá. O certo é que mais uma vez a criatividade humana insurge-se como meio eficaz de realizar novas modalidades de performances e novas metodologias de ensino performático, o que de certa maneira revolucionará a forma como a música se processará no futuro.

É certo que fatores culturais e sociais podem influenciar sobremaneira o processo criativo. Como relatam Eunice Vaz Yoshiura et al. (1999, p. 15) a criação humana deve ser concebida como algo que extrapola a concepção e realização da mensagem a ser veiculada e as possibilidades criativas que as novas tecnologias oferecem são usadas como veiculação de conhecimento em seu significado antropológico. Portanto, a criatividade é pensada como uma forma de conhecimento capaz de romper com uma ordem anteriormente veiculada. Ela surge mais enfaticamente em momentos de crise sociopolítica e ambiental que demandam soluções rápidas. Como relata o físico quântico Amit Goswami:

Uma crise é um verdadeiro clarim capaz de despertar o seu potencial criativo. [...] Crises e mudanças de paradigmas andam de mãos dadas [...] Einstein dizia que não podemos resolver nossos problemas ficando no mesmo estado de entendimento em que eles foram criados. Por isso, necessitamos de uma mudança de paradigma, de uma mudança de visão de mundo. [...] Os paradigmas ou modelos de todos os sistemas de conhecimento tornam-se mais sofisticados com o tempo, o que pode ser bastante intimidador. [...] nos estágios iniciais de um novo paradigma, remetemo-nos de volta ao básico. Pensamentos simples, não sofisticados, são suficientes para que se faça um real progresso (GOSWAMI, 2012, p. 31-32). 
Este físico afirma ainda que a motivação criativa só se manifesta na demanda de uma crise - uma crise exterior, aos moldes da crise da sobrevivência civilizada que enfrentamos em nossos dias, ou uma crise interior, de intenso sofrimento, que a vida traz para alguns indivíduos. Todo mundo pode ser criativo quando sente a premência, seja ela uma motivação interior ou exterior. Para tanto, a motivação é essencial para que haja um ambiente criativo (GOSWAMI, 2012, p. 42).

Ao se reportar as artes, Amit Goswami relata que nessa área de conhecimento a validade do antigo jamais é posta em questão. Os paradigmas antigo e novo coexistem pacificamente, cada qual tendo o seu próprio direito. Nesse sentido, intui-se que ainda que haja mudanças futuras no campo performático, o velho e o novo estarão sempre interligados. Vejamos o relato desse físico quântico quanto a essa questão:

Ele (Picasso) deu início ao novo paradigma do cubismo observando um objeto de diferentes perspectivas - na mesma obra de arte. Esse novo paradigma reflete o caráter multidimensional da cultura do século $20 \mathrm{e}$ muda para sempre o modo como apreciamos toda e qualquer arte, presente e passada, sem jamais diminuir nossa apreciação da antiga (GOSWAMI, 2012, p. 222).

Esse relato nos permite intuir que as razões que levaram os profissionais da música e docentes a criar novas formas de disseminação da música e novas metodologias de ensino da performance podem, no futuro, redundar em posicionamentos bastante benéficos para o cenário performático, desde que salvaguardados os aprimoramentos tecnológicos e virtuais que necessariamente deverão ocorrer. Inúmeros trabalhos musicais experimentais ocorreram após a instauração dessa pandemia, eles vieram para democratizar e desterritorializar a produção musical. A criatividade foi expressiva dentro da crise instaurada. Isso, entretanto, poderá trazer para a sociedade e para o ensino performático, critérios de apreciação musical bastante diferenciados dos modelos veiculados anteriormente. Implicações culturais, sociais e até mesmo financeiras surgirão, sendo que a criatividade e a experimentação se farão presentes em grande escala. As escolhas serão variadas e o aprimoramento tecnológico e virtual que já aconteceu no passado e que trouxe bons frutos para área, poderá ocorrer novamente.

Reconheço que a performance, seja em forma de produção musical, seja na modalidade de ensino, não poderá ser inteiramente virtual. A música, como todas as demais artes, precisa do contato presencial, mas remodelações refletidas e aprimoradas 
poderão ser muito úteis para ampliar e estender a produção musical para um número maior de agregados e aficionados da música e principalmente trazer a música mais próxima da coletividade. Os desajustes e ajustes serão inúmeros, mas a verdade, é que diante do cenário instaurado, os profissionais da música souberam tirar partido no sentido de não deixar a música perecer nos locais de propagação.

Sigo este texto apresentando alguns depoimentos de profissionais que, durante a pandemia, realizaram atividades musicais experimentais até então não adotadas. Eles apontam as dificuldades encontradas, o aumento considerável de indivíduos que puderam assistir a essas atividades e relatam ainda, quais os benefícios e prejuízos caso essas práticas se intensifiquem no futuro.

\section{Experiências artístico-musicais de profissionais e docentes de performance durante a pandemia}

Os depoimentos que se seguem relatam em que medida as práticas musicais virtuais realizadas por professores de performance e profissionais de música contribuíram para a continuidade de um trabalho performático em tempos de pandemia, quais as dificuldades e benefícios encontrados e como essas ações virtuais se estenderão para o futuro.

\section{Depoimento de Valdemir da Silva, ${ }^{3}$ enviado via e-mail no dia 22 de outubro de 2020. Autorizada a publicação.}

"Neste depoimento, relato a forma como foram realizados dois concertos virtuais no Theatro Municipal de São Paulo, depois da instauração no planeta da COVID-19 que provocou o isolamento social, impedindo a realização de eventos artísticos e culturais, entre outros, os quais fiz parte integramente do processo de produção. O primeiro "Homenagem à Naomi Munakata", com a obra Ubi Caritas, de Maurice Duruflé, publicado no dia 31 de maio de 2020 (https://www.youtube.com/watch?v=ZCvYHmAj8Q) e o segundo, que integra a campanha “Arte Presente” foi a Suíte dos Pescadores", de

\footnotetext{
${ }^{3}$ Doutorando do Programa de Pós-Graduação em Música no Instituto de Artes da Universidade Estadual Paulista - UNESP. Bacharel em Composição e Regência, pela UNESP. Foi Regente Assistente da Banda Municipal de Mauá, vencedor do $1^{\circ}$ Concurso Nacional de Arranjos para Banda Sinfônica, Arquivista Musical da OSESP e Assistente de Direção da Escola Municipal de Música de São Paulo. Atualmente é Gerente do Coral Paulistano do Theatro Municipal de São Paulo.
} 
Dorival Caymmi e arranjo de Damiano Cozzella, publicado no dia 31 de agosto de 2020 (https://www.youtube.com/watch?v=TmA7LvUOokY\&t=137s).

Esses concertos virtuais foram realizados com o propósito de manter os músicos em atividade, evitando-se o sucateamento da programação artística ali realizada e possível futuras demissões de funcionários temporários, receio corrente entre os colaboradores. A prática artística à distância configurou-se como uma atividade inédita, um novo padrão e um nova realidade, muito necessária para preservar a continuidade das realizações musicais, ainda que de forma não ideal. Nesse sentido, a prática vocal virtual foi necessária para que os músicos mantivessem a sua estabilidade, seu desempenho e sua saúde física e mental.

A análise da estrutura pessoal e dos equipamentos disponíveis de cada cantor foi essencial para que pudéssemos dimensionar as possibilidades de realização dessas atividades. Foi necessário verificar os tipos e modelos de celulares, aplicativos, computadores, sistemas operacionais, capacidades software, hardware, microfones, fones que melhor se adequassem para a nova proposta de apresentação. Também foi imprescindível avaliar a familiaridade que os músicos tinham com esses equipamentos, de forma a manter a qualidade artística esperada pelo público ouvinte.

Horas de assessoria e treinamento foram investidos para que todos se adaptassem e tivessem a mesma condição de participar dos projetos propostos. Informações como um simples entendimento e conhecimento do equipamento, como se comportar diante da câmera, tipo de vestuário propício, maquiagem, luz, distância, cenário, ambiente, acústica, dia e horário mais ideal para gravação, formatos de áudio e vídeo foram transmitidos aos músicos coralistas sempre que necessário.

Vários tutoriais foram criados para auxiliá-los, tais como: acessar o drive compartilhado, para fazer download e upload no drive, como utilizar WhatsApp Web, como filmar com o celular, configurações de áudio e vídeo. Esses procedimentos foram transmitidos e ensinados incessantemente, vistos, revistos e atualizados, tanto de forma coletiva quanto individualmente.

Mesmo no caos instaurado e nas transformações ocorridas, processos foram realizados de maneira que todos pudessem ter acesso e entendimento dos recursos tecnológicos. Esses procedimentos exigiram maior comprometimento dos participantes. 
Os coralistas, por exemplo, se sentiram cada vez mais expostos para exibir suas qualidades musicais.

É claro que neste momento, diferentemente das práticas rotineiras precedentes à pandemia, onde tudo era organizado para um espetáculo ao vivo, com muitas pessoas aplaudindo, apreciando e prestigiando a performance dos artistas, as alternativas referentes ao repertório se tornaram mais restritas. Como garantir ao público o gosto da vivência e a experiência de desfrutar as diversas sensações oferecidas, semelhante às que eram quando participavam presencialmente? E ao cantor que depende da percepção de espaço e tempo para dar sentido à música e completar o todo? Um concerto virtual é bem diferente de uma atividade artística presencial. Estar ao vivo, perceber e sentir a plateia, permitem melhor absorção e pode favorecer a reação física gerada pelo evento. Contudo há que ser dito que o alcance público obtido com essas apresentações foi imenso, ainda que as atividades corais se desenvolveram conforme as possibilidades.

Os cantores não estavam reunidos de corpo presente à frente da maestrina, cercados por colegas cantores. Sua atuação estava limitada à uma tela de celular, computador ou outra espécie de monitor de onde recebiam orientações, habituando-se ainda, a uma nova forma de regência. A finalidade primordial era executar a música, enviar o áudio ou vídeo, sem o ajuste fino. O problema maior concentrou-se em como avaliar o conteúdo recebido. A maestrina teve que desenvolver novas metodologias para a direção, condução e forma de transmissão de seu pensamento interpretativo acerca do discurso musical.

Diante dessas transformações abruptas, novos conhecimentos e tecnologias foram adquiridos e implantados. Se anteriormente não havia o hábito de gravar as atividades, os concertos e as apresentações nem mesmo para registro dos conteúdos realizados, teve início uma grande preocupação com essa rotina. Pois como confirmar algo sem registro?

Teve início, então, uma nova etapa do cotidiano institucional. Inicialmente os técnicos de som e integrantes da comunicação abraçaram as tarefas que não eram fáceis. Durante várias semanas "Plantões de Dúvidas" foram realizados para que se pudesse homogeneizar todos os processos relacionados a essa nova realidade e oferecer uma arte final de qualidade, cuja finalidade também era a de amenizar o sofrimento, solidão e angústia que o isolamento estava causando nas pessoas. 
Foi necessário adotar algumas medidas para um bom desenvolvimento dessas atividades, entre elas: limpar a lente do aparelho celular e checar o nível da bateria; o aparelho celular deveria permanecer bloqueado, para não receber ligações, mensagens ou notificações, durante as gravações; verificar qual a melhor opção de qualidade e resolução da câmera do celular - Full HD (1920x1080); preocupar-se com o posicionamento de câmera, na horizontal, padrão TV ou vertical e enquadramento da sua imagem; preocuparse continuadamente em fornecer dicas de posicionamento e estabilidade na filmagem, utilização da luz para que o vídeo não ficasse muito escuro, nesse sentido, como utilizar a luz frontal, seja ela natural ou artificial, proveniente de uma lâmpada ou luminária; criar um cenário organizado e harmonioso ou neutro com parede clara; identificar o material no sentido de dizer o nome e o projeto no início das gravações, assim como renomear o arquivo a ser enviado (Projeto $\mathrm{N}^{\mathrm{o}}$ /Naipe / Nome / Cantor); utilizar o fone de ouvido, além de sugerir qual o melhor aplicativo ou software.

Aparentemente estes processos poderiam parecer simples, mas está longe de ser. Para garantir o mínimo de sincronia dos áudios e vídeos e facilitar a edição e mixagem, deve haver uma linha de produção racional e muito bem planejada a fim de se mitigar os possíveis problemas ou inutilização do material.

Os projetos se iniciaram com a concepção artística, escolha da música e divisões das fases ou etapas conforme os objetivos e prazos. A primeira etapa ou pré-produção foi destinada à preparação do material, como partitura, contendo marcações para interpretação uniforme e padronizada (cortes, dicção, respirações e fraseados). Esse material foi enviado aos cantores com vídeo explicativo e nesse momento foi decidido se a música seria gravada em seções menores. Além disso, foram criados drives para depósito dos arquivos e orientações técnicas para gravação; verificação e pagamento de taxas referentes à liberação de uso da partitura e direitos autorais.

Também foram decididos os delineamentos artísticos e cênicos que serviram de apoio visual e nortearam a proposta artística. É importante a criação da agenda de entregas individuais, assim como para os ensaios virtuais, em naipes e com todos os cantores, para o processo de gravação. Essas ações têm finalidade de promover a comunhão entre os artistas, tranquilizá-los e deixá-los mais à vontade para produção do material audiovisual 
solicitado. Por isso, para garantir a sincronia na hora de editar, houve a preparação do áudio-guia ao piano, voz e piano e produção do vídeo de regência.

A segunda etapa, com duração aproximada de vinte dias, foi destinada à produção. Esse período foi dedicado aos ensaios virtuais, deliberações e soluções referente às dúvidas, preparação e realização da gravação individual (cantores), entrega da gravação (depósito do arquivo no drive compartilhado), análise do conteúdo por parte da direção artística e maestrina, além do feedback para possíveis ajustes e correções.

Caso houvesse parte para piano, a gravação seria realizada anteriormente ao início das gravações de cada voz individualmente e posteriormente às realizações de ensaios para servir como base aos cantores.

$\mathrm{Na}$ terceira etapa que perdurou por mais vinte dias, foi o momento em que se iniciou todo o processo de fechamento e finalização do produto, roteirização e elaboração de orientações destinadas à edição, montagem e mixagem de áudio, vídeo e/ou áudio/vídeo dos materiais oriundos de fonte individual e distinta. Foi necessário disponibilizar os arquivos às equipes de som, áudio, vídeo, comunicação e produção por meio do compartilhamento dos drives e pastas, contendo todo material de forma organizada e decupada para prosseguir com a edição do som captado e arranjo da disposição dos vídeos e fotos, ou seja, o gerenciamento das entradas marcadas na partitura/roteiro de cada coralista em uma determinada posição de tempo na música - em uma time code.

A finalização, última etapa deste trabalho, demorou cerca de cinco dias. Foi o momento de tomar as decisões finais, avaliação do produto, pequenos ajustes no acabamento, inserção de encartes, ficha técnica, legenda, vídeo da maestrina, quando necessário e parte do contexto, parecer final e publicação com acesso gratuito nas mídias sociais e fechamento do relatório com descrição de todo o processo.

Como se pode observar, trata-se de uma nova modalidade de apresentação artística, onde tudo é feito separadamente, pois cada integrante do coral se reúne virtualmente em uma sala de reunião, dessas oferecidas pelo Google, Zoom, Skype etc. - para discutir e discorrer a respeito da música proposta, até mesmo praticá-la on-line, para depois, longe dos colegas, que em outros tempos estariam próximos, estudar, preparar-se e ensaiar para realizar futura e remotamente, uma obra coral. 
Trata-se de uma nova modalidade de apresentação que certamente será incorporada, com todas as ferramentas nas próximas realizações corais, pelo menos enquanto perdurar o isolamento social. É um novo processo, em que obtivemos inúmeras descobertas e aprendizados, tudo imposto pelas dificuldades geradas pela pandemia gerada pela COVID-19. Nada será igual ao que era antes, mas o mundo segue com novas transformações e expectativas, mais um capítulo da vida das pessoas e da rotina artística.

Como será depois dessa pandemia? Não sabemos. Mas temos consciência que novos horizontes virão e que este é um momento de transição e aquisição, inclusive, de diferentes maneiras para se construir uma performance coral, onde as relações musicais, humanas e tecnológicas se integram. Apresentações on-line configuram-se como o novo palco. Mesmo tendo esperança que essa pandemia termine, sabemos que essa nova rotina futuramente será agregada e incorporada às práticas "tradicionais". Ações, técnicas e metodologias vêm sendo expandidas e permanecem em constante aperfeiçoamento sempre em vista ao desenvolvimento e isso pode fornecer um novo caminho artístico para o futuro."

\section{Depoimento da pianista e professora de piano Maria Elisa Ferreira Risarto, ${ }^{4}$ enviado via e-mail, no dia 23 de outubro de 2020 . Foi autorizada a publicação.}

"No ano de 2020 fomos surpreendidos por uma pandemia provocada pelo vírus COVID-19, que afetou todos os aspectos da vida humana; países inteiros foram colocados em quarentena para preservar a vida, evitando o contágio da doença. Nós que trabalhamos com o ensino da performance fomos prejudicados pelo desconhecimento das novas tecnologias, pelo consequente despreparo sobre alternativas, aplicativos e meios tecnológicos plausíveis de serem usados, no sentido de proporcionar ao público em geral e aos alunos de instrumento a continuidade do trabalho musical.

No meu caso, como musicista e pianista que sou, tive dificuldade de dar continuidade aos projetos musicais que havia marcado para o primeiro semestre de 2020 .

\footnotetext{
${ }^{4}$ Maria Elisa Risarto é mestre em música pelo IA-UNESP, pós-graduada em piano e especialista em Interpretação Musical pela FMCG. Bacharel em Economia pela PUC-SP. Foi assistente do Prof. Gilberto Tinetti e pianista da Orquestra Sinfônica Jovem de São Paulo por vários anos. Participou do Projeto 500 anos de amizade Brasil - França com o Duo Risarto- Grossi. Participou da gravação do CE Villa Lobos em Paris sob a direção de Gil Jardim. Foi assistente de direção e professora de piano da Escola Municipal de Música. Atualmente faz parte do corpo docente da Faculdade de Música Santa Marcelina.
} 
Todos foram cancelados. Porém, tive a sorte de ser brindada com a chance de participar de uma live com a Orquestra de Câmara Miller, pois havíamos marcado apresentações do Concerto de Bach em Ré menor para piano e orquestra. Os ensaios presenciais foram suspensos e então, houve a ideia de realizarmos esse trabalho a partir da gravação do $2^{\circ}$ movimento daquele concerto. Todos se animaram e através de um guia, cada um dos participantes da orquestra fez um vídeo apresentando a sua parte. Graças ao esforço da Patricia Carvalho Aguiar, violoncelista, pudemos realizar este vídeo ${ }^{5}$.

Foi uma experiência muito significativa para mim, que estou habituada desde sempre a fazer música de câmara, ou acompanhar cantores e/ou músicos, onde dependo de toda sua expressividade musical para fundamentar e mesclar a sonoridade e o timbre do piano, o ritmo, dinâmicas, rallentandos, acellerandos, respirações e outros tantos elementos que complementam esta prática musical tão específica.

Quanto ao trabalho didático, junto à FASM - Faculdade de Música Santa Marcelina, estamos tentando resolver o problema de atraso na chegada do som, ao tocamos juntos. O aplicativo Zoom está sendo usado com sucesso em aulas coletivas de performance, mas o delay (atraso em relação ao tempo da execução) atrapalha e torna quase impossível as práticas de conjunto como coral, música de câmara, orquestra de câmara e mesmo ensaios acompanhando cantores e instrumentistas de cordas do curso de bacharelado e regência.

Minha alternativa, no caso dos ensaios com cantores e instrumentistas, foi gravar áudios de todas as partes que os alunos necessitam para estudo e/ou aulas com seus professores de canto e cordas. No caso de aulas de regência, aconteceu o mesmo. Temos tentado diminuir o delay nas aulas via Zoom, ou utilizando outros aplicativos, mesmo assim, o aluno sempre vai ouvir o piano atrasado em relação ao seu gesto, então, a alternativa tem sido os alunos gravarem vídeos com sua regência (sem som) e eu tocando durante a aula virtual, direcionando a minha câmera do celular para o laptop, onde todos possam visualizar o regente e o som do piano ao mesmo tempo.

Tudo isto é muito frustrante, porque a prática musical de conjunto, no instante em que ela acontece, requer a fusão entre as pessoas e o som dos instrumentos. Esta fusão

\footnotetext{
5 Disponível em: https://www.orquestramiller.com.br/videos.
} 
sonora, envolvendo cantores, músicos ou regentes é aperfeiçoada por todos, em aulas, ensaios e estudos individuais que são também necessários para que cada um resolva seus problemas técnicos na peça em questão.

Nas aulas de leitura à primeira vista ao piano, quando trabalho com os pianistas que participam das aulas de práticas de conjunto, passei a atender um aluno por vez, via Zoom ou até via WhatsApp, quando o sinal está falhando e atrapalhando a aula. Como o material a ser utilizado na aula deve ser desconhecido do aluno, tenho enviado algumas obras para piano solo via internet, para serem trabalhadas durante cada aula. Depois de o aluno executar o trecho musical escolhido por mim, conversamos virtualmente sobre os aspectos que o aluno necessitaria melhorar, em cada caso.

Aqui também sinto que as aulas ficam prejudicadas, porque presencialmente, além de peças para piano solo, fazemos também leituras à primeira vista de peças escritas para serem tocadas ao piano a quatro mãos. Neste caso, os pianistas são colocados de forma a ler as duas claves (a de Sol e a de Fá), e durante todo o tempo, dependendo das peças, eles são obrigados a trabalhar com a mudança de clave. Com este trabalho, preparamos o aluno para estar à frente do teclado pianístico em diversas localizações, sabendo que a leitura de claves será aperfeiçoada. Essa tarefa, em um ambiente virtual, não tem a mesma eficiência, contudo, foi a maneira encontrada para não interromper as atividades pedagógicas voltadas para o estudo performático. Com relação aos concertos virtuais, apesar de não me parecer a melhor opção, eles têm possibilitado aos músicos em geral, não interromperem suas atividades."

\section{Depoimento da Prof. Dr. Flavia Albano de Lima, ${ }^{6}$ professora de canto lírico na Universidade Federal da Bahia, enviado por e-mail no dia 08 de outubro de 2020. Autorizada a publicação.}

"Quando em 19 de março deste ano nos vimos forçados a ficar em nossas casas em razão da pandemia do Coronavírus, não imaginei que depois de sete meses ainda

\footnotetext{
${ }^{6}$ Flavia Albano é doutora em Educação: Currículo pela Pontifícia Universidade Católica de São Paulo (PUC-SP), mestre e especialista em performance musical pelo Royal Northern College of Music, bacharel em Canto Erudito, licenciada em Música pela Faculdade de Música Carlos Gomes e habilitada em artes dramáticas pelo Teatro Escola Macunaíma. É docente na graduação e na pós-graduação profissional da Escola de Música da Universidade Federal da Bahia (UFBA), onde ministra disciplinas ligadas ao Canto Lírico, além de coordenar o Laboratório de Ópera EMUS-UFBA.
} 
estaríamos dentro delas. Enquanto professora, nunca tive contato com nenhum tipo de ensino à distância e, como aluna, participei somente dos cursos de capacitação do INEP. Entretanto, durante os últimos meses descobri que o ensino online pode ser proveitoso e agradável. Basicamente, estou ministrando as mesmas disciplinas que ministraria no semestre regular, considerando que minha carga horária é centrada no ensino tutorial de canto aos alunos do Bacharelado em Canto Lírico.

Percebi que dependo muito da boa vontade da internet, da minha e também da de cada aluno. Passei por vários momentos muito frustrantes, um deles ocorreu quando um dos meus melhores e mais interessados alunos demorou 20 minutos para estabelecer a conexão com a internet e quanto conseguiu, ela era tão ruim que eu não conseguia ouvir um só nota que ele cantava. Naquele dia tivemos que encerrar a aula.

Para além do problema de conexão, encontrei um outro, ou seja, nenhuma plataforma, mesmo em condições ideais de conexão, é fiel aos sons emitidos pelo canto. Os sons emitidos por vibração labial, bocca chiusa ou com instrumentos facilitadores, como o canudo, são identificados com ruídos e são suprimidos, isso sem contar o delay de cerca de 1 ou 2 segundos entre o que eu toco no piano e o que o aluno canta. Existe também a necessidade de ver mais de perto a postura, a posição da língua, eventuais tensões - tudo impossível pelo vídeo. Nesse caso é preciso confiar nas sensações do aluno e no que consigo ouvir desta produção vocal.

Entretanto, nem tudo é negativo, pois graças à tecnologia meus alunos não ficaram sete meses sem aulas de canto, o que seria devastador. Muitos alunos do primeiro ano do Bacharelado tiveram três aulas presenciais e, com a pandemia, passaram a ter suas aulas online.

Mesmo com todos os problemas relatados, observei que todos tiveram um certo progresso. Aos poucos vou me acostumando a fazer aquilo que é possível e deixar para outro momento o que o momento não me permite. Uma das práticas desenvolvidas que promovi foram as oficinas de idioma. Nessa atividade pedi aos alunos que, depois de seminários em idiomas, me mandassem áudios de WhatsApp dos textos das obras que estavam cantando - textos falados, declamados, no ritmo da música, - o que presencialmente nunca tiveram paciência de fazer. Ainda em relação ao desenvolvimento de repertório, apoiamo-nos no trabalho de dedicados pianistas acompanhadores que 
deixavam as partes de piano gravadas em seus canais de Youtube, para que estudantes pudessem cantar em cima dessa base e assim foi possível estudar seu repertório mesmo sem a presença de um pianista correpetidor. Talvez uma das minhas mais empolgantes descobertas foi a iniciativa de criar um diário de estudos, onde os alunos postavam as sensações que tiveram ao estudar sozinhos naquele dia. Esse diálogo me permitiu dedicar um tempo muito maior a entender as sensações e aflições de cada aluno no que tange ao trabalho técnico e, considero que no cotidiano do estudo presencial, provavelmente não teríamos nos dedicado a isso com tanto afinco.

Basicamente, a experiência virtual no estudo da performance musical tem seus impeditivos, em nada supera a interação no aqui e no agora do fazer musical, mas é preciso perseverar e entender o que é possível fazer neste momento que estamos vivendo. Obviamente eu voltaria, sem pestanejar, para as aulas presenciais, entretanto, algumas descobertas, como o envio de vídeos e áudios para os alunos, a utilização do diário de estudos e até uma eventual aula a distância para um aluno que está fora da cidade, ou que não conseguiu vir por um motivo justificado, poderão ser procedimentos pedagógicos que permanecerão para o futuro.”

\section{Depoimento da Profa. Dra. Shirlei Escobar Tudissaki, ${ }^{7}$ enviado em 21 de outubro de 2020, por e-mail. Autorizada a sua publicação.}

“Como grande parte das escolas de música no Brasil, a Escola Municipal de Iniciação Artística (EMIA), durante a pandemia ocasionada pela COVID-19, teve de suspender as aulas presenciais com os alunos e oferecer aulas virtuais.

Até o início da pandemia, eu era bastante reticente às aulas de instrumento de forma virtual. Hoje em dia vejo que esta atitude se deu por conta de nunca ter trabalhado com

\footnotetext{
${ }^{7}$ Doutora e Mestra em Música pela UNESP. Possui Pós-graduação Lato Sensu em Educação Especial pela UNIRIO e Bacharelado em Piano pela USC. Atualmente é Professora do Programa de Mestrado Profissional em Artes da UNESP, Professora-artista da EMIA e Instituto Fukuda. Atuou como Professora da Licenciatura em Educação Musical da UFSCar; Coordenadora e Professora da Pós-graduação Lato Sensu em Educação Musical da FACEC/Alpha; Professora da Pós-graduação Lato sensu em Metodologia do Ensino de Música do IBPEX; Coordenadora e professora do setor de Educação Musical do Conservatório de Tatuí; Regente, Supervisora musical e Coordenadora pedagógica dos 29 livros didáticos do Projeto Guri (AAPG). Coautora dos livros $1^{\circ}$ Encontro Científico de Música e Interdisciplinaridade da UNESP e Protagonistas do ensino musical. É autora do livro Ensino de música para pessoas com deficiência visual, lançado em 2015, pelo selo Cultura Acadêmica, da Editora UNESP. Contato: shirleiescobar@gmail.com.
} 
aulas de piano utilizando recursos tecnológicos, bem como por conta da minha inabilidade em lidar com os programas para execução de videochamadas.

Eu já havia lecionado na Universidade Federal de São Carlos (UFSCar), na Licenciatura em Educação Musical semipresencial, com parte das atividades utilizando a plataforma Moodle - ferramenta de apoio ao ensino à distância.

$\mathrm{Na}$ EMIA fui contratada para dar aulas de piano presenciais para as crianças até 12 anos de idade. Com a pandemia, estas aulas passaram a ser virtuais. Tanto os alunos da EMIA como os meus alunos particulares, começaram a ter aulas por videochamadas, pois considerei ser a melhor forma de interagir com a classe. Com essa modalidade de aulas eu poderia resolver as questões técnicas e interpretativas durante a execução instrumental, respondendo aos questionamentos dos alunos de forma dialógica, muito semelhante ao processo pedagógico vivenciado nas aulas de piano presenciais.

No início da pandemia (março de 2020) as dificuldades foram enormes, somadas a minha inabilidade em lidar com os recursos tecnológicos. $\mathrm{Eu}$ me questionava continuadamente: Qual o melhor posicionamento para a câmera? Quais as possibilidades de configuração para o microfone? Será que os alunos estão compreendendo o que eu quero dizer? Aos poucos esses questionamentos foram sendo solucionados. Ainda temos problemas de conexão lenta, câmera e microfones de alunos que não funcionam a contento, bem mais amenos do que no início do processo. Estes questionamentos me levaram a estudar e aprofundar meus conhecimentos com relação aos recursos tecnológicos e verificar as possibilidades de cada um dos programas que seriam utilizados, entre eles, o Zoom, Google Meet, Skype e até mesmo WhatsApp, para os alunos que não possuíam conexão $W I-F I$ em casa.

Durante os meses que se passaram, consegui configurar os programas, de modo a melhorar a captação dos sons do instrumento, para que estivessem o mais próximo possível da "sonoridade real", bem como encontrar o melhor posicionamento para a câmera na casa de cada um dos alunos, de modo que eu pudesse visualizar as mãos e a postura deles no instrumento.

Percebo que nesses meses, meus alunos de piano estão participando das aulas virtuais de forma bastante animada e até mesmo mais ansiosos para apresentar o que estudaram durante a semana. Eles têm estudado piano como nunca haviam estudado. 
Conseguimos organizar um plano de estudos adequado para cada um e posso afirmar que aproximadamente $80 \%$ deles está estudando o instrumento todos os dias. Houve um salto técnico e musical incrível em apenas alguns meses de trabalho. O sucesso das aulas virtuais foi tão grande que consegui organizar dois eventos virtuais, com apresentações ao vivo dos alunos, cada um em sua casa. Foram momentos de conexão e, especialmente, de emoção, com alunos e público compartilhando momentos de intimidade com o seu instrumento, dentro de suas próprias casas.

Outro ponto positivo foi o retorno que obtive dos pais de alunos, agradecidos e emocionados com a continuidade das aulas de piano durante essa pandemia. Posso dizer que essas mensagens recebidas trouxeram luz e conforto para meus dias de distanciamento social. Fico muito feliz em poder contribuir com o bem-estar dessas crianças e famílias em um momento tão delicado como esse que estamos vivendo. É realmente um privilégio continuar com um ensino performático, ainda que seja à distância.

Acredito que mesmo quando as questões de saúde voltarem à normalidade, as aulas virtuais ainda continuarão em alguns casos. Dois alunos particulares, por exemplo, estão de mudança para outro estado e seus pais já me comunicaram que pretendem continuar com essas aulas à distância. Na verdade, trata-se de uma realidade da qual não poderemos escapar no futuro.

Penso que as aulas presenciais nunca deixarão de existir, mas as aulas online estão facilitando e continuarão facilitando a vida dos professores e alunos. É inegável que o ensino presencial de instrumento oferece inúmeras vantagens, tanto com relação à sonoridade do instrumento "real", quanto à correção da postura, o "tocar junto" com o aluno, entre muitos outros fatores. Apesar disso, o ensino de instrumento à distância pode e deve ser utilizado de forma positiva, como um recurso pedagógico importantíssimo para o professor de música.

No que diz respeito às audições presenciais, estas não serão substituídas pelas audições online, mas nada impede que as apresentações em modo virtual continuem ocorrendo, uma vez que facilitam o acesso a todas as pessoas que possuem uma conexão com internet, em qualquer local do planeta." 


\section{Considerações Finais}

Concluindo este texto, declaro que os depoimentos e argumentos até agora relatados evidenciam que para o futuro o setor artístico-musical deverá fazer uso de uma tecnologia de melhor qualidade para que as produções virtuais sigam de forma menos improvisada. Também será necessário que os músicos em geral e professores de performance utilizem essa tecnologia com melhor desenvoltura. Isso demandará um gasto excedente tanto para as instituições culturais como para as escolas de música em geral.

Embora essa questão não tenha sido veiculada é importante retratar que as relações trabalhistas neste setor deverão sofrer inúmeras modificações, para que músicos em geral e professores de performance não sejam prejudicados em suas remunerações. Não podemos imaginar para o futuro, que o trabalho realizado por esses profissionais siga de forma caótica como tem sido até agora. Professores, músicos e produtor de espetáculos têm trabalhado exaustivamente, às vezes gratuitamente, para cumprir as tarefas que até então eram executadas presencialmente. Os contratos de trabalho desses profissionais exigirão cláusulas específicas, até então não incorporadas nos contratos atuais, principalmente com relação ao trabalho domiciliar que não está sendo computado.

É certo que as instituições culturais (casas e espaços culturais, teatros e salas de concerto) responsáveis por essas produções, tiveram prejuízos consideráveis com essa pandemia. É quase certo que para o futuro elas irão repensar quais produções serão preservadas, vão rever seus gastos, reformularão suas temporadas, para que o setor musical não caia no ostracismo, principalmente os voltados para a música erudita. $\mathrm{O}$ mesmo há que se pensar para as escolas de música. De que forma se processará o ensino da performance, como conciliar uma educação presencial e uma educação virtual?

Esses são alguns dos procedimentos a serem avaliadas em um futuro próximo. Embora o setor musical tenha resistido nesse período conturbado mediante criações e experimentações das mais variadas, fato que afastou o sucateamento desta área de conhecimento, mas para o futuro, esses mecanismos de sobrevivência deverão ser reavaliados.

Finalmente digo que não podemos imaginar a música sendo ofertada ao público sob um crivo iminentemente virtual. Ela está presente como pano de fundo em boa parte 
das atividades artísticas, seja no cinema, no teatro, nos espaços culturais em geral, mas ouvir música presencialmente ainda é uma ação que se faz necessária. Nesse período de pandemia, assisti a inúmeros concertos e recitais pelo YouTube, vi inúmeros documentários, aulas online, assisti a inúmeros DVDs, lives, sem considerar os cursos que foram ofertados na mídia. Contudo, depois de um longo período afastada dos concertos presenciais, fui assistir a uma apresentação musical na sala São Paulo e de repente percebi o quanto meu corpo, minha mente e meu espírito estava impregnado por aquela esfera sagrada para a qual a música nos conduz. Isso ainda não poderá ser extinto e nesse momento eu compartilho da fala do físico quântico Amit Goswami, quando relata que nas Artes a validade do antigo jamais é posta em questão; o paradigma antigo e o novo coexistem pacificamente, cada qual tendo seu próprio direito. Assim dito, intui-se que as mudanças do futuro não afetarão as práticas musicais anteriores.

Sob essa perspectiva, o texto de Camila Fresca intitulado Lições da pandemia, publicado na Revista Concerto, em outubro de 2020, traz uma mensagem bastante promissora com respeito às transmissões online realizadas pelas principais orquestras brasileiras durante a pandemia, contemplando depoimentos de seus regentes e diretores artísticos. O diretor artístico da Filarmônica de Minas Gerais assim se manifestou:

\footnotetext{
Contrariamente a outras formas de arte, tanto nós, músicos, quanto nosso público acreditamos que nada substitui a experiência viva de fazer música. Mas também estamos aprendendo que existem outras ações paralelas que podem vir a ser incorporadas ao leque das atividades (Revista Concerto, outubro de 2020, p. 8).
}

No final de seu relato, Camila Fresca declara que essa nova forma de atuação surge como uma nova frente de oportunidade para os músicos, porém terá de ser aprimorada, transformando o concerto ao vivo em um novo produto pensado para o meio digital, o que requer profissionais especializados. Não se trata, portanto, de substituir o evento presencial, mas de garantir uma nova experiência estética. 


\section{Referências}

ALBANO DE LIMA, Flavia. Depoimento, enviado em 08 de outubro de 2020.

CÂMARA DE CASTRO, Marcos. Além da partitura: ou elementos para uma musicologia da performance. In. ALBANO DE LIMA (org.) Performance sob uma perspectiva pluralista. Aguardando publicação. São Paulo: Musa Editora, 2020.

FRESCA, Camila. Brasil Musical, Lições da pandemia. Revista Concerto, outubro de 2020, p. 8.

GOSWAMI, Amit. Criatividade para o século XXI: Uma visão quântica para a expansão do potencial criativo. São Paulo, Aleph, 2012.

MAIORINO, A. V.; COLABARDINI, J. C. M.; GABRIEL, F. O Festival Internacional de Música em Casa: tecnologias, aprendizagens e práticas musicais em tempos de COVID-19. No prelo, 2020.

MOJOLA, Celso. A gravação e a performance ao vivo. Texto inédito, elaborado em dezembro de 1999.

RISARTO, Maria Elisa. Depoimento, enviado em 23 de outubro de 2020.

SILVA, Valdemir da. Depoimento, enviado em 22 de outubro de 2020.

TUDISSAKI, Shirlei Escobar. Depoimento, enviado em 21 de outubro de 2020.

YOSHIURA, Eunice Vaz, YÁZIGI, Eduardo e SPINELLI, João J. O porquê e como de um congresso de criatividade no Brasil. In: YOSHIURA, Eunice Vaz, YÁZIGI, Eduardo e SPINELLI, João J, YÁZIGI, Latife (organizadores). Criatividade - Uma busca interdisciplinar. São Paulo: UNESP, 1999. 